\title{
Violence against Women: Survivors Need the Support of All
}

\section{Saurabh RamBihariLal Shrivastava* and Prateek Saurabh Shrivastava}

Department of Community Medicine, Shri Sathya Sai Medical College and Research Institute, Tamil Nadu, India

Violence directed against women is a major violation of fundamental human rights and often accounts for grave short and longterm consequences [1]. The global estimates revealed that almost $35 \%$ of women have been exposed to physical and/or sexual violence at least once in their life [2]. This means that the survivors of violence can be anyone ( $v i z$. sisters, wives, friends, patients, etc.) in our vicinity [1-3]. In other words, these estimates are quite alarming and clearly suggest that it is a global concern, which has been reported in all settings and areas of life $[1,3]$.

Since violence against women, children and adolescents force many survivors to seek health services, we must ensure that regardless of where care is provided, it has to be fair, dignified and offered without any discrimination $[3,4]$. It is important to acknowledge that the survivors of violence still find it difficult to open about their sufferings and often their wounds open up once they share their incidents of abuse, and this is the area where health system can play a defining role [4]. In order to deal effectively with the situation, the World Health Organization (WHO) is taking steps to strengthen the health system [3].

Health systems are in a position to play an indispensable role, which comprises of identification of the victims of violence \& provide them with holistic package of services, fostering linkages with other sector to provide women the benefit of other needed support, prevent the recurrence of violence episodes by addressing the potential causes, educate survivors \& the local community about the consequences of violence $\&$ the necessity to seek timely care, estimation of the precise magnitude of the problem \& its predisposing factors, and advocating for coordinated multi-sectoral prevention and delivery of effective care [1-5].

Furthermore, the offered health care response should be womencentric, which means that the attempted measures should improve their safety, consider their views, provide care based on their needs in a comprehensive manner, offer them information to help them to take informed decisions, and finally empower them in such a way that they can involve themselves in their own care [3-5]. Moreover, while offering care, the health workers should provide care without discrimination, advocate gender equality, never inquire about violence unless a woman is alone, and should not harm by asking the survivors to repeatedly tell their story or judge them $[1,4]$.

In addition, the WHO has formulated an action plan on the global scale to ensure that all the women and girls are never exposed to any forms of violence or discrimination [3]. In addition, it calls for promotion \& protection of their health and well-being, and preservation of their basic human rights $[1,3]$. Also, women have been encouraged to share their stories and how they approached the situation in social media in the last few weeks to create awareness about the problem, and at the same time help them to open up about their sufferings [3].

To conclude, violence against women is a major global public health concern, and all efforts should be taken to minimize the incidence of violence and help them to lead a normal life with the help of assistance from different sectors.

\section{References}

1. Shrivastava SR, Shrivastava PS, Ramasamy J (2017) Aiming to target gender barriers for improving the health and welfare standards of girls. Ann Trop Med Public Health 10: 527-528.

2. World Health Organization (2017) Violence against women.

3. Askew I (2017) Survivors of sexual and physical abuse need \#youtoo.

4. World Health Organization (2017) Strengthening health systems to respond to women subjected to intimate partner violence or sexual violence: A manual for health managers.

5. Baigorria J, Warmling D, Magno Neves C, Delziovo CR, Salema Coelho EB (2017) Prevalence and associated factors with sexual violence against women: Systematic review. Rev Salud Publica (Bogota) 19: 818-826.
*Corresponding author: Saurabh RamBihariLal Shrivastava, Department of Community Medicine, Shri Sathya Sai Medical College and Research Institute, Tamil Nadu, India, Tel: 919884227224; E-mail: drshrishri2008@gmail.com

Received: August 20, 2018; Accepted: September 20, 2018; Published: September 27, 2018

Citation: Shrivastava SR, Shrivastava PS (2018) Violence against Women: Survivors Need the Support of All. Prim Health Care 8: 304. doi: 10.4172/2167-1079.1000304

Copyright: @ 2018 Shrivastava SR, et al. This is an open-access article distributed under the terms of the Creative Commons Attribution License, which permits unrestricted use, distribution, and reproduction in any medium, provided the original author and source are credited. 